\title{
Public Risk Perception and Risk Communication of Typhoon Disaster
}

\author{
Zhihai Shang, Liping Li \\ Department of Geography, Lingnan normal university, Zhanjiang 524048, China
}

Received 14 October 2016

Accepted 5 November 2016

\begin{abstract}
Public risk perception is the basis for effective natural disaster risk communication, and the latter can strongly influence the former. Take typhoon disaster as an example, this paper constructs the theory model of 12 factors affecting risk perception from three dimensions by public individual characteristics, risk situational characteristics, risk communication efficiency, which influence the input, output and transmission of risk information. Then the theory was applied in typhoon disaster in Zhanjiang city, and it comes out that the theory is reliable. Finally, the contents of typhoon disaster risk perception capacity construction were given in this paper as risk communication capacity building, special platform construction and cultural environment of risk communication, which is the only way for effective risk communication.
\end{abstract}

Keywords: risk perception; risk communication; typhoon disaster

\section{公众台风灾害风险认知与风险沟通探讨}

\author{
尚志海, 李丽苹 \\ 岭南师范学院地理系, 广东 湛江 524048
}

\begin{abstract}
摘 要: 公众灾害风险认知是自然灾害风险沟通的基础, 风险沟通又强烈地影响着风险认知。以台风灾害 为例, 首先构建了自然灾害风险认知影响因素的理论体系, 从风险信息的输入、输出和传播三个方面, 提 出公众个体属性、风险情景特征及风险沟通效率 3 个维度的 12 个影响因素。接着, 将灾害风险认知影响因 素的理论应用于湛江市台风灾害实践中加以检验, 研究结果验证了理论的可靠性。最后, 提出有效风险沟 通是提升公众风险认知能力的唯一路径, 通过政府风险沟通能力、风险沟通专门平台和风险沟通文化环境 建设来实现有效风险沟通。
\end{abstract}

关键词：风险认知；风险沟通；台风灾害

《2015 2030 年仙台减少灾害风险框架》提出, 为实现仙台框架的预期成果和目标, 第一个优先领 域是理解灾害风险, 其中就包括风险沟通与交流 ${ }^{[1]}$ 。 自然灾害风险沟通是灾害风险利益相关者之间的交 流工具, 风险沟通的基础是了解公众风险认知 ${ }^{[2,3]}$ 。 以往的经验显示, 无论风险评估技术和结果多精细, 它本身也不大可能引发公众主动参与减灾行动 ${ }^{[4]}$ 。
一般来说，高水平的风险认知才会激发人们采取风 险管理措施 ${ }^{[5,6]}$ 。自然灾害风险沟通对公众风险认知 有着直接的影响, 风险沟通方式不当, 很容易导致 公众产生认知上的偏差 ${ }^{[7]}$ 。

从 20 世纪 60 年代开始, 西方学者就进行了灾 害风险认知研究 ${ }^{[11]}$, 探讨了公众风险认知的影响因 素 ${ }^{[8-10]}$, 并进行了滑坡、洪水、地震、台风灾害风 
险认知与风险沟通的理论与实践探索 ${ }^{[12-16]}$ 。汶川地 震发生后, 国内学者才开始关注灾害风险认知与风 险沟通研究, 但是研究进展不大 ${ }^{[17]}$, 分别以 “灾害 认知”、“灾害感知”、“灾害沟通”为检索词, 在中国期刊网中对论文篇名进行模糊检索, 结果显 示到 2016 年 8 月 31 日为止上述三类期刊论文数量 仅分别为 58 篇、 26 篇和 16 篇。由此可见, 国内灾 害风险认知与风险沟通研究亟待加强, 尤其是台风 等极端灾害事件的风险认知研究。

台风是中国沿海地区普遍发生且破坏力极强的 自然灾害, 本文提出了公众灾害风险认知及其影响 因素的理论模型, 并将其应用于湛江市居民台风灾 害风险认知研究中, 最后提出了公众台风灾害风险 认知能力提升, 即有效风险沟通的建设内容。

\section{1. 研究方法与数据来源}

在理论体系构建上, 本文采用历史文献法, 综 合运用灾害学、心理学、社会学等多学科的理论, 诠释台风灾害风险认知及其影响因素之间的关系。 在灾害实证分析上, 本文采用问卷调查法, 对湛江 市进行实地调研获得真实数据, 并对调查数据进行 统计分析, 从而得到相应的研究结果。

\section{1 调查问卷设计}

本问卷的设计包括两个部分: 个人基本信息; 台风灾害风险认知和风险沟通情况。第一部分具体 包括被调查者的性别、年龄、居住地点、文化程度、 从事职业; 第二部分包括被调查区域台风灾害的易 发性与危害性, 台风灾害对居民的心理伤害, 灾害 风险信息获取渠道, 居民对灾害预警信息的响应情 况等。正式调研之前, 笔者进行了预调查, 并根据 调查结果对正式调查问卷进行了完善, 使其更加切 合本次调查的目的, 可以更真实地了解湛江居民对 台风灾害的认知情况。

\section{2 调查地点选取}

本文的研究区域为湛江市, 台风是湛江市典型 灾害, 每年平均会有 1 2 个台风登陆, 而且湛江市 是广东沿海地区台风灾害风险最大的城市 ${ }^{[18]}$ 。例如, 2015 年 10 月 4 日第 22 号台风 “彩虹” 以强台风级 在湛江市坡头区沿海登陆, 登陆时中心最大风力达 16 级, 是 1949 年以来十月登陆广东最强的台风。 在 “彩虹” 作虐下, 湛江市遭受了极大损失, 直接 经济损失约为 210 亿元。由于台风 “彩虹” 给中国 南部造成严重影响, 在美国檀香山举行的第 48 届台 风委员会会议上, 中国提出将 “彩虹” 除名。

湛江市现辖雷州市、吴川市、廉江市 3 个县级 市, 徐闻县、遂溪县 2 个县和赤坎区、霞山区、坡 头区、麻章区与湛江市经济技术开发区, 其中雷州 市和徐闻县是遭受台风灾害侵袭最频繁的区域。根 据湛江市台风灾害的空间特征及历史灾情, 本次调 查选取了“彩虹” 重灾区坡头区、遂溪县及台风易 发区雷州市和徐闻县作为样本点, 同时以随机抽样 方法调查这四个区域 235 名居民对台风灾害的认知 情况, 各个样本点的调查数量基本一致, 所占比例 都在 $25 \%$ 左右。

\section{3 基本情况统计}

本次调查是在台风 “彩虹” 发生 3 个多月后, 于 2016 年 1 月 10 日至 26 日实施。共发放问卷 235 份, 回收问卷 235 份, 其中无效问卷 24 份, 最终有 效问卷 211 份, 有效回收率 $89.8 \%$ 。样本数据的基 本情况统计是指对有效调查问卷的全部被调查者的 基本信息数据进行一个统计性表述, 了解样本的大 致状况。调查样本中男女比例分别为 $47.9 \%$ 和 $52.1 \%$, 相差不大; 按照联合国人口年龄划分标准, 样本以 18 44 岁的青年人为主, 占了总数的 $60.7 \%$; 绝大多数具有中等及其以上的教育背景, 小学及以 下学历的被调查者只占 $9 \%$; 从职业构成来看, 在校 学生和农林牧渔业生产人员的比例最高, 占了总数 的 $61.1 \%$ 。 


\section{2. 公众灾害风险认知及其影响因素分析}

\section{1 理论模型}

风险认知是人们的主观心理活动, 它是用来描 述人们对风险的态度和直觉判断的概念, 广义上也 包括人们对风险的一般评估和反应 ${ }^{[8]}$, 同时也反映 了灾害利益相关者之间风险沟通的效果。不同的人 对灾害的风险认知是有差异的。Slovic 认为风险认 知的影响因素有两个基本维度: 忧虑性维度和未知 风险维度 ${ }^{[7]}$ 。谢晓非等认为至少有 15 种风险认知影 响因素: 自愿性、可控性、熟悉性、公正性、利益、 易理解性、不确定性、恐惧、对机构的信任、可逆 性、个人利害关系、伦理道德、自然或人为风险、 受害者特征、潜在的伤害程度 ${ }^{[9]}$ 。在前人研究的基 础上 ${ }^{[19]}$, 根据公众感知和评估灾害风险信息的过程, 本文认为灾害风险认知的影响因素可以概括为公众 个体属性、风险情景特征、风险沟通效率三个维度, 分别对应着 “谁来感知、感知什么和如何感知” 。 公众个体属性影响着风险信息的输入，风险情景特 征影响着风险信息的输出, 风险沟通效率作用于风 险信息的传输过程, 三者共同作用塑造着公众灾害 风险认知的特征（表 1）。

表 1. 公众灾害风险认知的影响因素

\begin{tabular}{cl}
\hline 三个维度 & \multicolumn{1}{c}{ 具体因素 } \\
\hline \multirow{2}{*}{ 公众个体属性 } & 自然属性: 性别、年龄 \\
\cline { 2 - 2 } & 社会属性: 文化程度、从事职业 \\
\hline \multirow{2}{*}{ 风险情景特征 } & 灾害易发性、灾害距离感、 \\
& 事件危害性、灾害恐怖感 \\
\hline \multirow{2}{*}{ 风险沟通效率 } & 信息清晰度、信息可信性、 \\
& 信息可达性、公众响应度 \\
\hline
\end{tabular}

公众个体属性包括公众个体的自然属性和社会 属性, 自然属性包括性别、年龄, 两者对灾害风险 认知的影响比较复杂, 虽然学者们都认为它们之间 有联系，但是其复杂程度也不容忽视。在不同性别 人群的灾害风险认知差异研究上, 目前有三种不同
观点: 一是女性的灾害认知程度不如男性 ${ }^{[20]}$; 二是 女性的灾害认知能力强于男性 ${ }^{[21]}$; 三是男女在灾害 风险的认知上基本相同 ${ }^{[22]}$ 。而从年龄特征来看, 灾 害认知能力最强的年龄段也有差别, 包括: $20 \sim 30$ 岁、19 25岁以及40岁以上等 ${ }^{[20-22]}$ 。公众个体的社会 属性包括文化程度、从事职业。社会属性比自然属 性与灾害风险认知的关系更清晰，一般来说，公众 文化程度越高, 其对灾害风险情景的评估越理性, 对灾害风险信息的理解越清晰, 获取灾害风险信息 的渠道越广泛，信息越能被准确、及时地传递给居 民本人，风险沟通的参与度和话语权越大。公众从 事的职业与其经济水平有直接联系, 经济水平越高, 灾害风险认知意愿和能力越强。

风险情景特征包括灾害易发性、灾害距离感、 事件危害性、灾害恐怖感, 这四个因素分别从灾害 的时、空、强三个特征影响公众灾害风险认知, 灾 害的强度包括客观特征和主观感受两个方面。首先, 灾害易发性影响着公众对灾害的熟悉程度，风险认 知程度会随灾害熟悉程度不同而不同。第二, 灾害 距离公众的远近，包括空间距离和时间距离也会影 响公众灾害风险认知; 公众对灾害的风险认知程度 会随时空距离增加而降低。第三，人们往往更看重 灾害事件的危害性，而不是其发生频率 ${ }^{[23]}$ 。死亡与 失踪人数、直接经济损失集中显示了灾害的危害性, 因此极大地影响着公众的风险认知。最后, 灾害恐 怖感影响着公众在面临灾害时的情绪和心理, 灾害 事件所导致的恐慌，其危害程度可能远远大于灾害 本身 ${ }^{[9]}$ 。灾害越恐怖, 越能引起公众的风险认知, 这正是地震比干旱更能引发公众关注的原因。

风险沟通效率包括信息清晰度、信息可信性、 信息可达性、公众响应度。灾害风险信息本身的性 质与传播环境都会影响风险认知，体现为风险信息 是否清晰、是否可信与可达。信息的清晰度和可信 性是公众接收及关注信息的基础, 人们不会在模糊、 可疑的信息上浪费时间和精力。灾害风险信息的可 
达性要通过风险沟通渠道来实现。只有通过传统媒 体和新媒体帮助公众建立理性的风险认知, 才能将 灾害的负面影响降低到可接受水平 ${ }^{[24]}$ 。此外, 灾害 风险沟通效率的构建依赖于沟通各方的互动过程, 除了需要政府、专家、媒体传播信息外, 还需要公 众积极响应, 才能实现有效沟通, 风险沟通又强烈 地影响着风险认知。

\section{2 实证分析}

\subsection{1 公众个体属性与风险认知的关系}

（1）自然属性

不同性别居民的台风灾害风险认知水平不同, 具体来说, 湛江市居民中男性对防灾减灾实践技能 的掌握程度好于女性; 但是就台风灾害理论知识的 了解程度来说, 女性强于男性。另外, 不同年龄段 的居民, 其台风灾害风险认知表现出不同特征。调 查显示: 湛江市居民中对台风灾害知识掌握最好的 是 30 44 岁年龄段的人群, 而对防灾技能掌握最好 的则是 45 59 岁年龄段的人群。

（2）社会属性

随居民文化程度的不断提高, 湛江市居民的台 风灾害风险认知水平及防灾减灾能力也不断增强, 大专及以上学历人员对台风灾害的认知水平最强, 初中或高中学历人员对台风灾害的认知水平较强, 小学及以下学历人员对台风灾害的认知水平最弱。 在不同从业人员中, 对台风灾害的认知水平及其防 灾减灾能力差异较大, 以国家机关、企业单位职工 认知水平最高。

通过上述分析, 可以发现: 在影响湛江市居民 台风灾害风险认知的公众个体属性中, 性别虽有影 响, 但是男女在不同风险认知能力上各有千秋, 性 别对灾害风险认知的影响要具体问题具体分析; 30 60 岁中青年的风险认知水平最强, 随着年龄的 不断增长, 台风防灾减灾经验也是不断丰富的; 湛
江市居民的公众灾害风险认知水平与受教育水平成 正相关，也与从事职业有一定关系。

\subsection{2 风险情景特征与风险认知的关系}

（1）灾害易发性

台风是湛江市最频繁的自然灾害, 居民早已对 其习以为常, 并积累了一定的抗台经验。调查结果 显示: 居民对台风登陆前的防范措施是基本一致的, $81.0 \%$ 的居民会提前准备好食物、饮用水、手电筒、 蜡烛和常用药品; $75.8 \%$ 的居民会修检房屋和加固门 窗; $58.3 \%$ 的居民会检查家中电路、煤气等设施的安 全情况。正是因为灾害易发性增强了公众的风险认 知水平, 所以他们才会有相应的防灾减灾行为。

(2) 灾害距离感

本文的调查对象都位于湛江市，与台风的空间 和时间距离都很近，居民对台风灾害风险的感受都 很深。尤其是 $80.6 \%$ 的居民都认为 2015 年的 “彩 虹” 对他们的影响大, 其中又有超过一半的人认为 台风对其生活影响非常大, 58.3\%的居民受到的最大 影响是停电。这一情况也与事实一致, 彩虹发生期 间湛江市区几乎全城停电停水，通信中断。刚刚发 生在公众身边的台风灾害, 无疑会给他们带来巨大 的冲击, 会使他们对台风灾害风险有更深的认知, 大多数人会及时改善风险应对行为。

（3）事件危害性

台风是湛江市最严重的自然灾害, 调查显示湛 江居民认为台风灾害造成的影响主要以财产破坏和 出行不便为主, 经济损失是对居民最大的危害。湛 江市每年平均会有 1 2 个台风登陆, 由于台风的不 确定性和多变性, 难以把握其规律, 每次台风都造 成重大损失。但即使台风灾害经常发生, 如果其给 居民造成的不利影响很小甚至可以忽略不计，那么 台风作为一种自然事件也不足以引发人们的关注。 这也许可以用来解释为什么有 $55.5 \%$ 的湛江市居民 对台风灾害信息的关注度较低, 因为遭受直接损失 
的人毕竟是少数。

\section{（4）灾害恐怖感}

根据问卷调查和现场访谈显示, 台风造成的居 民心理情绪的变化主要表现为居民的负面情绪及认 知。每次台风灾害后, 居民心理都会产生不同程度 的变化, 当谈及台风灾害时, 他们都表现出伤心、 悲愤和害怕的情绪, 其中认为台风会造成心理恐慌 的人群比例高达 $60.7 \%$ 。湛江市虽然也面临其他自 然灾害的影响, 比如干旱、暴雨, 但与台风相比, 其恐怖感偏低, 因此不会产生像台风一样的强的负 面心理, 也就没有引发公众足够的灾害风险认知。

湛江市台风灾害频发, 居民与台风灾害的时空 距离都近在迟尺, 且灾害危害严重, 民众心理恐慌 程度高, 因此上述影响因素综合在一起, 极大地影 响着公众灾害风险认知。

\subsection{3 风险沟通效率与风险认知的关系}

（1）信息清晰度、可信性和可达性

与其他自然灾害相比, 台风灾害预警信息的清 晰度和可信性都较高, 一般是由政府应急办、三防 办、气象部门联合发布, 例如台风 “彩虹” 的预警 信息非常详细, 中央气象台 10 月 3 日 23 时 30 分发 布台风红色预警：今年第 22 号台风 “彩虹” 已于今 天（3日）晚上 11 点钟由台风级加强为强台风级,

晚上 11 点钟其中心位于海南省文昌市以东大约 210 公里的南海北部海面上。预计, “彩虹” 将以每小时 20-25 公里的速度向西偏北方向移动, 强度继续加 强, 最强可达 15-16 级, 并将于 4 日上午在海南文 昌到广东湛江一带沿海登陆。此外, 预警信息还包 括大风预报和降雨预报。
从上述信息可以发现, 台风灾害风险的信息越 清晰，比如灾害发生时间、空间、强度的信息越明 确, 公众越能及时做出响应; 并且随着台风的登陆, 台风灾害信息会更清晰明确, 这也会增强公众对灾 害风险的认知。如湛江市对台风彩虹的预警级别从 橙色上升到黄色, 直至红色预警, 通过预警级别的 提升, 也从侧面反映了风险信息的清晰度和可信性, 因此公众会根据台风级别的提升, 加深对台风灾害 风险的认知，从而采取适当的防灾减灾措施。

在台风灾害风险信息的可达性方面，目前政府 相关部门主要利用电视、广播、互联网、手机短信 等渠道向社会发布预警信号。在这些信息渠道中, 被调查者中 $85.3 \%$ 以上的居民是通过手机了解风险 信息, 之后是电视广播、电脑、亲友告知、社区宣 传、报纸杂志 (表 2)。从这些数据可以发现新媒体 在台风灾害风险沟通中的重要地位, 以手机短信、 微博、微信为代表的新媒体成为了人们获取风险信 息的最主要渠道, 其开放性、即时性、交互性特征, 增强了普通居民对灾害风险信息的获取与交换。

（2）台风风险沟通中的公众响应度

即使可靠的台风灾害风险信息表达清晰, 并且 及时传递到了公众手中，但是如果公众不积极对灾 害风险预警做出响应, 风险信息也只是单向的传递 而已。公众参与风险沟通的响应度主要表现在台风 来临前的准备和防护措施、台风来袭时的做法与表 现。调查结果显示: $91.5 \%$ 的居民表示接到台风预警 信号后, 就会及时做好防灾减灾准备。公众对灾害 风险信息的响应度越高, 说明公众的风险认知能力 越强, 越能积极应对灾害风险。

因此, 风险沟通效率的高低强烈地影响着公众

表 2. 公众对台风灾害风险沟通渠道的选择情况

\begin{tabular}{ccccccc}
\hline 排序 & 1 & 2 & 3 & 4 & 5 & 6 \\
\hline 沟通渠道 & 手机 & 电视广播 & 电脑 & 亲友告知 & 社区宣传 & 报纸杂志 \\
选择比例 & $85.3 \%$ & $68.70 \%$ & $66.80 \%$ & $28.00 \%$ & $25.10 \%$ & $11.80 \%$ \\
\hline
\end{tabular}


灾害风险认知水平的大小，只有发布清晰、可信、 可达的台风灾害风险预警信息, 公众才能真正地感 知灾害风险, 并积极响应, 从而最终降低灾害损失。

\section{3. 有效风险沟通是影响风险认知的关键}

在影响公众灾害风险认知的三大因素中, 公众 个体属性和风险情景特征一旦形成,一般难以改变, 因此提高公众台风灾害风险认知能力的关键在于提 高风险沟通效率。根据影响风险沟通效率的四个因 素, 本文提出从三个层面的建设来完善有效风险沟 通（表 3)，从而提高风险信息的清晰度、可信性、 可达性以及公众的响应度, 最终推动公众灾害风险 认知能力的提升。

表 3. 有效风险沟通的建设内容

\begin{tabular}{ll}
\hline \multicolumn{1}{c}{ 三个层面 } & \multicolumn{1}{c}{ 具体内容 } \\
\hline 政府风险沟通能力 & $\begin{array}{l}\text { 组织管理能力、风险评估能力、 } \\
\text { 沟通协调能力 }\end{array}$ \\
\hline 风险沟通专门平台 & 网络技术、手机终端、专门网站 \\
\hline 风险沟通文化环境 & 大众传媒、风险教育、社会参与 \\
\hline
\end{tabular}

\section{1 政府台风灾害风险沟通能力建设}

政府台风灾害风险沟通能力建设是风险沟通有 效实施的关键。政府灾害风险沟通能力包括组织管 理能力、风险评估能力、沟通协调能力。

政府的组织管理能力, 具体体现在风险沟通机 构、风险沟通制度、风险沟通保障、人员队伍配备。 与风险沟通及风险管理相比, 中国目前只重视应急 管理, 而忽视灾害风险管理。在应急管理方面, 根 据《中华人民共和国突发事件应对法》、《国家突 发公共事件总体应急预案》等的规定, 应急管理组 织结构比较完善, 国家层面有国务院应急管理办公 室，地方各级人民政府是本行政区域突发公共事件 应急管理工作的行政领导机构, 负责本行政区域各 类突发公共事件的应对工作。有了组织机构和制度, 其他方面的建设就迎刃而解了。因此, 建议政府有
关部门以应急管理为基础, 开展风险管理及风险沟 通的组织管理工作。

政府的风险评估能力非常重要, 风险评估结果 是风险信息的来源, 目前导致公众对政府风险管理 能力缺乏信心的一个重要原因就是公众不信任政府 的风险评估能力及结果。公开、公正、科学地进行 灾害风险评估和建立预警系统，是台风灾害风险沟 通工作的必然要求。政府的风险评估不仅仅是指其 工作人员进行的内部评估, 还应该广泛吸纳相关专 家和普通公众的评估, 使风险评估在尽可能广的范 围内实施。

在对公众的调查中，居民认为台风灾害风险管 理的不足，除了基础设施建设外，第二大不足就是 政府协调能力较弱。政府风险沟通协调能力的提升, 需要国家所有行政和立法机构在国家和地方各级充 分参与, 明确划分利益相关者的责任，包括专家、 媒体和公众的责任, 以确保伙伴合作、职责和问责 相得益彰。政府必须能够与其他利益相关者进行积 极的互动与协调, 才能把握民众的心理和行为动向。

总之, 只有政府部门做好风险沟通的顶层设计 与统筹协调, 公众才有可能在政府的帮助下获得清 晰、及时的风险信息，并增强对政府的信任度，从 而不断提升灾害风险认知水平和能力。

\section{2 台风灾害风险沟通专门平台建设}

有效风险沟通的开展需要沟通平台的辅助, 如 此利益相关者才能实现平等、及时、有效沟通，从 而提升公众的风险认知水平。以互联网为主要标志 的新媒体使得灾害风险信息海量出现, 并且散落在 政府网站、微博、微信等媒介中。另外, 新媒体的 出现使得灾害风险信息不再被政府和专家垄断, 每 个人都可以成为风险信息发布者。因此, 台风灾害 风险沟通专门平台建设非常重要。

目前灾害风险信息非常零散且陈旧, 即使在灾 害应急管理上也存在同样的问题。打开中国政府网 
一应急管理的网页 (http://www.gov.cn/yjgl/)，里面 的信息和动态还停留在 2014 年 2 月。全国第一个应 急管理专门网站是广东省人民政府应急管理办公室 网站, 虽然网站的内容比较丰富, 但是访问量较少, 没有起到风险沟通的应有作用。应急管理的经验提 醒政府管理者, 台风灾害风险沟通专门平台建设需 要注意两个关键问题：一是平台上的风险信息必须 进行数据分类 ${ }^{[17]}$; 二是政府应该重视基于新媒体的 沟通平台建设。

现有灾害风险应急沟通平台存在着沟通主体分 类和灾害信息分类不清, 缺乏互动尤其是即时互动 渠道。因此, 本文建议以网络技术为核心, 以手机 终端为载体, 建立自然灾害风险沟通专门网站, 考 虑到不同类别用户的需求, 以适当形式编制和更新 灾害风险数据和风险地图。此外, 要通过政务微博、 政务微信, 尤其是微信公众号收集意见、倾听民意、 发布信息、服务大众, 例如中国气象局官方微信, 可在此基础上建立灾害风险微信公众号。

因此, 政府管理者应该根据新时代灾害风险信 息传播的特征, 整合资源, 建立台风灾害风险沟通 专门平台, 并且公开、及时地与风险专家、媒体和 公众互动, 促进信息的分享与交流。

\section{3 台风灾害风险沟通文化环境构建}

风险沟通的有效实施不仅依赖于组织、人力和 硬件的建设, 还依赖于文化环境的构建。在风险沟 通时不能够脱离社会文化结构, 如果不了解社会文 化的价值和信仰, 就难以了解公众的风险认知, 也 难以进行有效的风险沟通 ${ }^{[25]}$ 。

风险沟通文化环境的构建很大程度上依赖于大 众媒体, 尤其是新媒体具有信息沟通、與论导向和 稳定社会的重要功能, 因此媒体在报道台风灾害时 应该秉承中立的原则, 不随意夸大缩小灾害风险。 以 2015 年台风 “彩虹” 和 2016 年台风 “妮妲” 的 报道为例，百度搜索中 “台风妮妲广州” 的信息量
是 “台风彩虹湛江” 的 5 倍多, 由此可见媒体报道 的偏好。在媒体和社会的关注下, 广州在妮妲登陆 前就启动全市 $\mathrm{I}$ 级应急响应, 这也是历史以来广州 市首次发布防台风防汛全民动员令，但最终台风只 是擦过广州南沙区。而湛江市在彩虹影响下全城停 水、停电数天, 交通和通讯受阻严重, 但主流媒体 只是在灾后才有少量报道。如何建立良好的媒体文 化也是风险沟通文化建设的重点。

除了大众媒体之外, 风险沟通文化的构建还有 赖于利益相关者的共同努力。在政府方面, 可以努 力发挥教育的功能, 尤其是学校教育, 使公众拥有 准确、恰当、充足的风险知识。在风险教育中, 政 府部门必须培育风险文化，并鼓励利益相关者参与 风险知识的教育与培训。另外, 在政府的引导下, 应鼓励全社会的积极参与, 且进一步增强专家、媒 体和公众的风险责任感，只有人们对其做出的决定 承担责任，才有可能实现灾害风险管理的目标，从 而推动包容、积极和非歧视的风险沟通文化建设。

风险沟通的完善过程也就是风险文化建构的过 程，有效的风险沟通应该使风险信息与文化情景交 融, 公众只有认可和接纳风险沟通文化, 其风险认 知水平才能真正提升。

\section{4. 结论}

在台风灾害风险管理的过程中，政府管理者只 有了解公众的风险认知特征, 发布清晰、可信、及 时的风险信息，并使风险预警被公众接受，才能使 风险沟通完成既定目标，有效降低灾害损失。本文 在理论和实证研究的基础上, 得出了以下结论:

（1）分析了 3 个维度的灾害风险认知影响因 素, 即公众个体属性、风险情景特征和风险沟通效 率, 每个维度又分别包括 3 个影响因素, 探讨了各 个因素对公众灾害风险认知的影响情况。（2）以湛 江市台风灾害为例, 具体分析了 12 个影响因素与公 众灾害风险认知的关系。研究发现, 湛江市居民的 
台风灾害风险认知特征及其影响因素与理论模型基 本一致。(3) 风险沟通是影响公众风险认知的关键, 有效风险沟通的建设包括风险沟通能力建设、风险 沟通专门平台建设和风险沟通文化环境构建, 从而 改善风险信息的清晰度、可信性和可达性, 努力打 造正面的公众参与风险沟通的文化环境, 实现有效 风险沟通。

致谢：本文受到国家自然科学基金项目（41606053 ）、广东省自然科学基金项目（2016A030310364） 和湛江市哲学社会科学 2016 年度规划项目 ( ZJ16YB09）资助, 在此表示感谢。

\section{参考文献:}

[1] The United Nations Office for Disaster Risk Reduction. Sendai Framework for Disaster Risk Reduction 2015 2030.[2015-03-18].http://www.unisdr.org/we/coordinate/sen dai-framework.

[2] 尚志海, 刘希林. 自然灾害风险管理关键问题探讨. 灾害 学, 2014, 29 (2): 159-164.

[3] Johnson B B. Risk Communication: A Mental Models Approach. Risk Analysis, 2002, 22 (4): 813-814.

[4] UNISDR. Global Assessment Report on Disaster Risk Reduction.[2015-12-04].http://www.preventionweb.net/engl ish/hyogo/gar/2015/en/home/index.html.

[5] Raška P. Flood risk perception in Central-Eastern European members states of the EU: a review. Natural Hazards, 2015, 79 (3): 2163-2179.

[6] Steelman T A, McCaffrey S. Best practices in risk and crisis communication: Implications for natural hazards management. Natural Hazards, 2013, 65 (1): 683-705.

[7] Slovic P. Perception of risk. Science, 1987, 236 (4799): 280-285.

[8] Gregory R, Mendelsohn R. Perceived risk, dread, and benefits. Risk Analysis, 1993, 13 (3): 259-264.

[9] 谢晓非, 郑芯. 风险沟通与公众理性. 心理科学进展, 2003, 11 (4): 375-381.

[10] Gierlach E, Belsher B E, Beutler L E. Cross-Cultural Differences in Risk Perceptions of Disasters. Risk Analysis, 2010, 30 (10): 1539-1549.
[11] Starr C. Social Benefit versus Technological Risk. Science, 1969, 165 (3899): 1232-1238.

[12] Li G M. Tropical cyclone risk perceptions in Darwin, Australia: A comparison of different residential groups. Natural Hazards, 2009, 48 (3): 365-382.

[13] Terpstra T, Lindell M K, Gutteling J M. Does communicating (flood) risk affect (flood) risk perceptions? Results of a quasi-experimental study. Risk Analysis, 2009, 29 (8): 1141-1155.

[14] Finlay P. J., Fell R. Landslides: risk perception and acceptance. Canadian Geotechnical Journal, 1997, 34 (2): 169-188.

[15] Maidl E, Buchecker M. Raising risk preparedness by flood risk communication. Natural Hazards and Earth System Sciences, 2015, 15 (7): 1577-1595.

[16] Ickert J, Stewart I S. Earthquake risk communication as dialogue-insights from a workshop in Istanbul's urban renewal neighbourhoods. Natural Hazards and Earth System Sciences, 2016, 16 (5): 1157-1173.

[17] 刘良明, 范一大, 李明, 等. 重大自然灾害风险沟通研 究. 北京: 测绘出版社, 2012.

[18］尚志海, 李晓雁. 广东省沿海地区台风灾害风险评价. 岭南师范学院学报, 2015, 36 (3): 136-142.

[19] 时振刚, 张作义, 薛澜. 核能风险接受性研究. 核科学 与工程, 2002, 22 (3): 193-198.

[20] 苏桂武, 马宗晋, 王若嘉, et al. 汶川地震灾区民众认知 与响应地震灾害的特点及其减灾宣教意义一一以四川 省德阳市为例. 地震地质, 2008, 30 (4): 877-894.

[21] 李景宜, 周旗, 严瑞. 国民灾害感知能力测评指标体系 研究. 自然灾害学报, 2002, 11 (4): 129-134.

[22] 戴薇. 广州居民灾害风险感知研究. 兰州: 兰州大学, 2014.

[23] 李华强，范春梅，贾建民，et al. 突发性灾害中的公众风 险感知与应急管理——以 $5 \cdot 12$ 汶川地震为例. 管理世 界, 2009, 25 (6): 52-60.

[24] 梁哲, 许洁虹, 李纾, et al. 突发公共安全事件的风险沟 通难题一一从心理学角度的观察. 自然灾害学报, 2008, 17 (2): 25-30.

[25] 王威. 风险沟通的文化变量分析. 新闻界, 2014, (24): 58-61. 